\title{
CORRECTION
}

View Article Online

View Journal I View Issue

CrossMark

\& click for updates

Cite this: RSC Adv., 2016, 6, 39015

DOI: $10.1039 / c 6 r a 90037 b$

www.rsc.org/advances

\section{Correction: The synthesis and ring-opening metathesis polymerization of glycomonomers}

\author{
Lucy G. Weaver, ${ }^{\text {a }}$ Yogendra Singh, ${ }^{a}$ Paul L. Burn ${ }^{\mathrm{b}}$ and Joanne T. Blanchfield ${ }^{* a}$
}

Correction for 'The synthesis and ring-opening metathesis polymerization of glycomonomers' by Lucy G. Weaver et al., RSC Adv., 2016, 6, 31256-31264.

The projections used to depict the disaccharides in Schemes 3 and 4 are of the wrong enantiomers and correct versions are shown below:<smiles>[Y]C(=O)[C@H]1C[C@H]2C=C[C]1C2</smiles>

$1 X=0$

$2 \mathrm{X}=\mathrm{NH}$

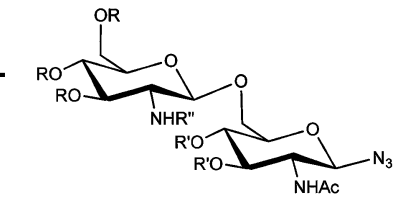

$8 \mathrm{R}=\mathrm{Ac}, \mathrm{R}^{\prime}=\mathrm{Bz}, \mathrm{R}^{\prime \prime}=\mathrm{TFA}$

$9 \mathrm{R}, \mathrm{R}^{\prime}, \mathrm{R}^{\prime \prime}=\mathrm{Ac}$

$10 \mathrm{R}, \mathrm{R}^{\prime}=\mathrm{Bz}, \mathrm{R}=\mathrm{TFA}$
Cu'Br, PMDETA, toluene, DMF*

$\mathrm{X}=\mathrm{O} \quad 88 \%(1+8)$ $\begin{array}{rl}\mathrm{X}=\mathrm{NH} & 60 \%(2+9)^{*} \\ 99 \%(2+10)\end{array}$

Scheme 3

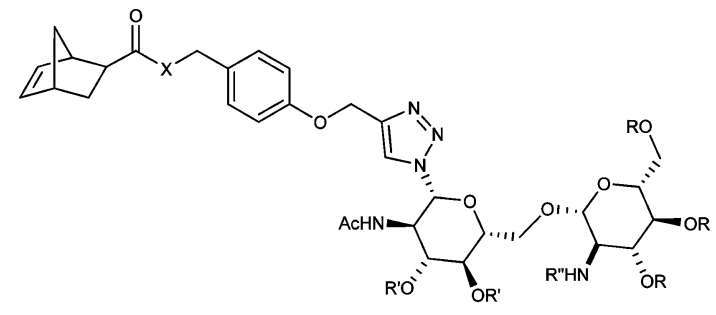

$X=0 \quad 15 \quad R=A c, R^{\prime}=B z, R^{\prime \prime}=T F A$

$X=N H \quad 16 \quad R, R^{\prime}, R^{\prime \prime}=A c$ $17 \mathrm{R}, \mathrm{R}^{\prime}=\mathrm{Bz}, \mathrm{R}=\mathrm{TFA}$
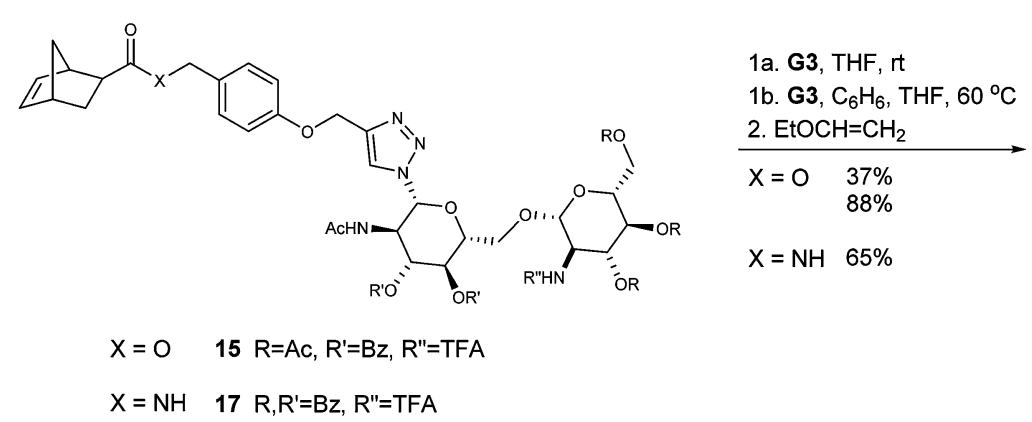

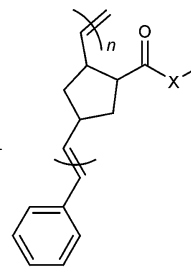

$\begin{array}{lll}X=0 & 18 R=A c, R^{\prime}=B z, R^{\prime \prime}=T F A \\ & 19 R=A c, R^{\prime}=B z, R^{\prime \prime}=T F A\end{array}$

$\mathrm{X}=\mathrm{NH} \quad 20 \mathrm{R}, \mathrm{R}^{\prime}=\mathrm{Bz}, \mathrm{R}^{\prime \prime}=\mathrm{TFA}$

Scheme 4

The Electronic supplementary information file is also updated to show the corrected structures of compounds 15-20.

The Royal Society of Chemistry apologises for these errors and any consequent inconvenience to authors and readers. 